\title{
Performance Analysis of FSO Link in Monsoon (Rainy) Season in Delhi, India
}

\author{
Soni Gupta
}

\begin{abstract}
In this paper, we present a comprehensive survey of attenuation due to rain conditions in the months of monsoon in Delhi region. In this paper I used Marshal and Palmer rain distribution model for four specific months of the rainfall i.e. June to September for calculate simulation model for rain attenuation. I analyzed Q-factor of the received signal by varying the transmission wavelength, data rate and range of the FSO system. The simulation results show that for error free transmission of data during the months of rainfall, the transmission signal wavelength in the longer wavelength region at a wavelength of $1300 \mathrm{~nm}$ and $1550 \mathrm{~nm}$ is recommended to be used for a maximum data rate of $2.5 \mathrm{~Gb} / \mathrm{s}$ with a maximum transmission range up to $4 \mathrm{Km}$. Delhi being a highly populated (with the IT hub) city the demand for higher and unlimited bandwidth for communication channel is highly required. For this case the communication through FSO is the best alternative solution than optical fiber.
\end{abstract}

KEYWORDS- FSO, FSO link, Mansoon season, FSO model

\section{INTRODUCTION}

Delhi is the capital of India, with huge population of 11 million in 2011 standing after Mumbai. With an area of $1484 \mathrm{~km}$ sqrs, it has seen a rapid growth up to 26 million in 2016 [1]. In this paper, we are proposing the use of FSO communication by presenting different parameters to be used in Delhi when transmitting data during the heavy rain period months, especially during the periods from June to September. We designed a model of FSO system using Opti-System to establish an FSO link by a range from 0 to 4 $\mathrm{km}$. while transmitting the data on NRZ modulation scheme, and reported analysis of various parameters like transmission power, Bit Error rate (BER), and transmission length[4]. The simulation results shows, for better transmission of data during the heavy rain seasons of the mentioned months above, the transmitting power of $5 \mathrm{dBm}$ should be used.

\section{Manuscript received August 13th, 2020}

Soni Gupta, Assistant Professor, Amity Institute of Aerospace Engineering, Amity University, Noida, U.P. 201313, India, (email:sgupta10@ amity.edu)
This power can be implemented within 0 to $4 \mathrm{~km}$ of the FSO links with an acceptable higher Q-factor. Also, for the transmission links should be $\mathrm{n}$ the range of 0 to $4 \mathrm{~km}$, a transmission power from the range of $-5 \mathrm{dBm}$ to $5 \mathrm{dBm}$ can be used respectively. The analysis also found that using FSO for communication is better than optical fiber because it can avoid some challenges such as high cost of digging roads, impractical physical connection between transmitters and receivers and insecure of data. We have collected the rainfall data for the years 2012-2016 during the months of monsoon i.e. June-September in the region and analyzed the extent upto which the performance of the link may be affected considering different values of transmission power, wavelengths, data rates and transmission ranges. Qualityfactor (Q-factor) as well as received optical power versus transmission distance has also been analyzed for the system.[8]

\section{SYSTEM LAYOUT OF PROPOSED FSO MODEL}

Working principle of Free Space Optical Communication (FSO) is that it operates on light propagation in a medium from one point to other. We used optisystem-15 for simulation and performance characterization. Optisystem15 is an innovative optical simulation package used for FSO designing, testing and optimization of virtually any type of optical system in the physical layer of spectrum of optical networks.

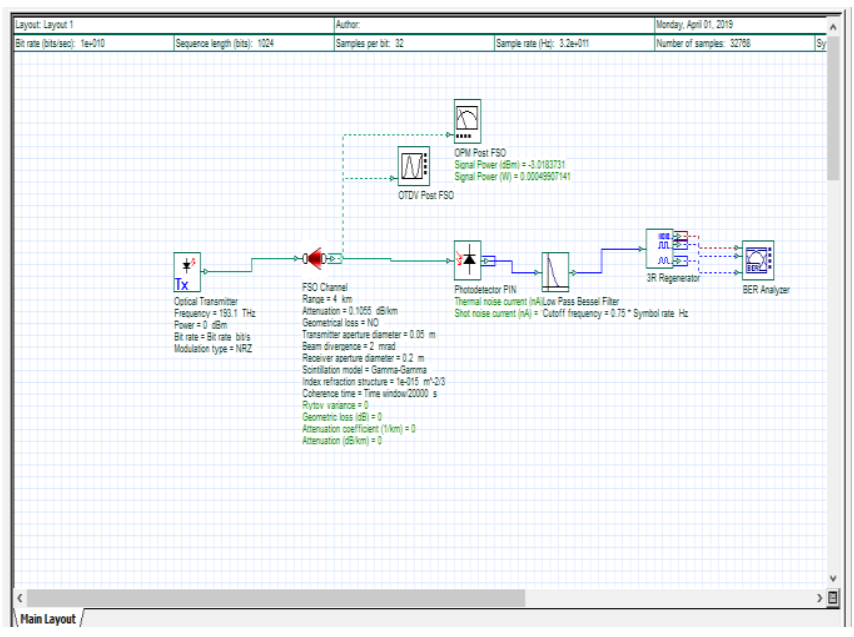

Fig 1: System model analyzing the effect of rain attenuation 
Performance Analysis of FSO Link in Monsoon (Rainy) season in Delhi, India

\section{DEGRADATION OF PERFORMANCE OF FSO LINK DUE EFFECT OF RAIN}

As per the dimensions of the raindrop, there are many distribution designs which may determine the Rain attenuation model [2]. We used marshal and palmer distribution model as rain attenuation model for analysis. Marshal and Palmer's distribution model is used to estimate the specific rain attenuation using an empirical formula [3]. The specific attenuation formula for rain effect analysis is:

$\gamma(\mathrm{dB} / \mathrm{km})=\mathrm{kR}^{\alpha}$

where $\mathrm{k}$ and $\alpha$ are constants whose values depend upon wavelength, temperature and rain drop size distribution and $\mathrm{R}$ is the rain rate in ( $\mathrm{mm} /$ hour). For spherical raindrops and operation at a wavelength of $1550 \mathrm{~nm}, \mathrm{k}$ and $\alpha$ are given as 1.076 and 0.66 respectively [5]. As the statistics given by the meteorological department is month wise in $\mathrm{mm}$, Average Rain per year during the months of monsoon has been computed as depicted in Table.1. It has been further converted to the Average Rain rate i.e. Rain/hour ( $\mathrm{mm} / \mathrm{hr}$.) per year for the months of rainfall [7]. The specific attenuation in $\mathrm{dB} / \mathrm{Km}$ per year has been calculated thereafter based on Average Rain rate as shown in Table.2.

Table 1: Rainfall data of Delhi Region for months JuneSeptember

\begin{tabular}{|l|l|l|l|l|l|}
\hline \multirow{2}{*}{ Year } & \multicolumn{4}{|l|}{ Rain (mm) } & $\begin{array}{l}\text { Average } \\
\text { Rain } \\
\text { (mm) }\end{array}$ \\
\cline { 2 - 6 } & June & July & August & September & \\
\hline 2012 & 7 & 113.4 & 222.6 & 65.8 & 408.8 \\
\hline 2013 & 110.9 & 189.3 & 177.9 & 58.4 & 536.5 \\
\hline 2014 & 27.1 & 111.1 & 80.0 & 71.2 & 289.4 \\
\hline 2015 & 58.9 & 268.8 & 244.7 & 26.1 & 598.5 \\
\hline
\end{tabular}

Table.2 Calculation of specific attenuation per year based on average Rain Rate $(\mathrm{mm} / \mathrm{hr}$.)

\begin{tabular}{|l|l|l|l|}
\hline & $\begin{array}{l}\text { Average } \\
\text { Rain (mm) }\end{array}$ & $\begin{array}{l}\text { Average } \\
\text { Rain Rate } \\
\text { (mm/hour) }\end{array}$ & Attenuation \\
\hline 2012 & 408.8 & 0.1396 & 0.1055 \\
\hline 2013 & 536.5 & 0.1832 & 0.1253 \\
\hline 2014 & 289.4 & 0.0988 & 0.0849 \\
\hline 2015 & 598.5 & 0.2044 & 0.1342 \\
\hline
\end{tabular}

Average attenuation $0.1225 \mathrm{~dB} / \mathrm{Km}$

\section{SIMULATION RESULTS}

Table 2: Default parameters

\begin{tabular}{|l|l|}
\hline Parameter & Value \\
\hline Data rate & 1000 \\
\hline Optical Tx Power & $-5 \mathrm{dBm}$ to $5 \mathrm{dBm}$ \\
\hline Wavelength & $1550 \mathrm{~nm}$ \\
\hline Modulation format & $\mathrm{NRZ}$ \\
\hline Transmitter Aperture & $0.05 \mathrm{~m}$ \\
\hline Receiver Aperture & $0.2 \mathrm{~m}$ \\
\hline Range & Upto $4 \mathrm{Km}$ \\
\hline
\end{tabular}

Rain attenuation prediction is normally referred as "specific attenuation" which means attenuation per unit length[7]. The most commonly use raindrop size distributions that have been proposed are Marshal and Palmer. In this paper Marshal and Palmer distribution proposed renowned empirical expression by fitting their data and the Laws and Parsons data[9]. The specific attenuation of wireless optical link for rain rate of $\mathrm{R} \mathrm{mm} / \mathrm{hr}$ is given by

Formula $\gamma(\mathrm{dB} / \mathrm{km})=\mathrm{a} \cdot \mathrm{Rb}$,

Where a $\&$ b are power law parameters equal to $0.365,0.63$ respectively.

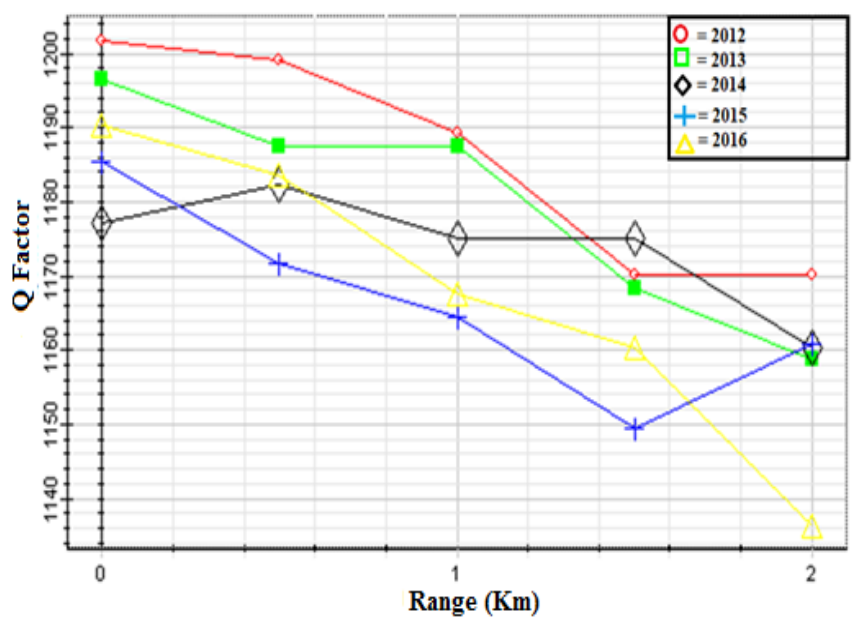

Fig 2: Quality factor of the received signal versus range (different years)

The graph in Fig.2 shows the max Q factor of the received signal versus range as a result of attenuations caused by rain in different years. We can observe an inverse relation between the two factors. 


\section{CONCLUSION}

In this paper, the rain attenuation used for simulation of the system has been calculated by using Marshal and Palmer rain distribution model model for four specific months of the rainfall i.e. June to September. We analyzed Q-factor of the received signal by varying the transmission wavelength, data rate and range of the FSO system. The simulation results show that for error free transmission of data during the months of rainfall, the transmission signal wavelength in the longer wavelength region at a wavelength of $1300 \mathrm{~nm}$ and $1550 \mathrm{~nm}$ is recommended to be used for a maximum data rate of $2.5 \mathrm{~Gb} / \mathrm{s}$ with a maximum transmission range up to $4 \mathrm{Km} .[6]$

\section{REFERENCES}

[1] Florence Upendo Rashid, SenzotaKivaria Semakuwa, "Performance Analysis of Free Space Optical Communication Under the Effect of Rain in Arusha Region, Tanzania”, Vol .3 Issue 9, September 2014.

[2] Hemani Kaushal, Georges Kaddoum, "Free Space Optical Communication: Challenges and Mitigations Techniques", 16 June 2015.

[3] Sushank Chaudhary, Angela Amphawan, "The Role and Challenges of Free-space Optical Systems" Journal of Optical Communications 35, no. 4, July 242014.

[4] Disha Srivastava and Gurjit Kaur, "Optimization of FSO System Parameters Under Varying Meteorological Conditions in Delhi" School of Information and Communication Technology, Gautam Buddha University, Greater Noida 201308, Uttar Pradesh, India, Volume 9 No. 1, 2017.

[5] Md Rafiqul, I., 2000. Rain Attenuation Prediction for Terrestrial Microwave Links Based on Rain Rate and Rain Attenuation Measurements in a Tropical Region. University of Technology Malaysia, Johor Bahru.

[6] G. Keiser, 2003. Optical Fiber Communications. Encyclopedia of Telecommunications.

[7] A.Nungu, B. Pehrson, "Interconnection of Broadband Islands in Developing Regions", IEEE 3rd International Conference on Testbeds and Research Infrastructures for the Development of Networks and Communities, Orlando, May 2007 (IEEE TridentCom 2007)

[8] F.U.Rashidi,S.K.Semakuwa,Analysis of Rain Effect in Free Space Optic Communication under NRZ Modulation in Two Regions of Tanzania,IJAENT, vol 1 ,Pg13-16,2014.

[9] T. H. Carbonneau, D. R. Wisely, "Opportunities and Challenges for Optical wireless", SPIE Conference on Optical wireless communication, Massachusetts, 1998, Pg $119-128$. 